\begin{tabular}{|c|c|}
\hline \multirow{3}{*}{ 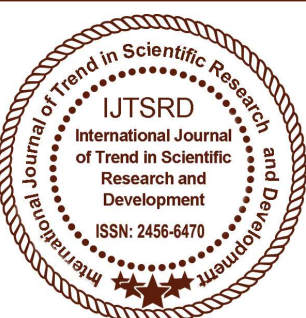 } & $\begin{array}{l}\text { International Journal of Trend in Scientific } \\
\text { Research and Development (IJTSRD) }\end{array}$ \\
\hline & International Open Access Journal \\
\hline & ISSN No: 2456 - 6470 | www.ijtsrd.com | Volume - 2 | Issue - 5 \\
\hline
\end{tabular}

\title{
A Study on Properties of Modified Rotor Spun Yarn
}

\author{
K. Gopalakrishnan \\ Lecturer Senior Grade, Department of Textile Technology, \\ Nachimuthu Polytechnic College, Pollachi, TamilNadu, India
}

\begin{abstract}
Fibers due to their large length-diameter ratio are the most effective materials in supporting tensile loads still. Many textile applications do introduce fiber compressions either in a simple form or under complex loading conditions. The majority of these compressive loadings are directed laterally across the fiber axis like compression of fibrous assembly during draftee. Compression occurring to fabric during calendaring and embossing treatments etc. A special pre-compression apparatus was fabricated and mounted before the entry of fibrous strand into opening roller of rotor spinning frame. Cotton Slivers were pre-compressed in this zone at varying loads and the effect of this pre-compression on the resultant yam has been studied. The yam properties considered for the study are the studies are $\mathrm{U} \%$, tenacity, elongation, hairiness and imperfections. The drawback with rotor spun yams is lower tenacity and elongation which always need an improvement. Modified rotor spun yams obtained as a result of pre-compression of slivers shows lesser $\mathrm{U} \%$, reduced thin, dick and naps, lower hairiness values and mainly improved tenacity, elongation and work of rupture which would be a vital point for the industry.
\end{abstract}

Keywords: Fiber, Neps, Tenacity, Spun Yarn

\section{INTRODUCTION}

Compressional properties of textile materials are important in some technological applications. The compressional properties of textile materials have direct relevance to bulk, handle of fiber masses, and structure of yarns and handle of fabrics. The compressional forces play an important role in the breakdown of pile fiber in the carpets. During drafting, fibers are compressed between a pair of rollers moving at a certain velocity and under a certain pressure. The fibers are compressed t higher twist factors in yarn. In knitting operation, the yarns are compressed to make them in the form of loop. The lateral compression property of yarn influences the material properties of fabrics to large extent. In weaving, the warp and weft yarns are compressed. The high performance fibers used in technical textiles like parachute fabrics, bullet proof vest etc., are also subjected to compressive forces during applications.

Thus in all stages of textile manufacture and also during applications, the textile materials are subjected to compressive stresses and strains. In the above context, it becomes crucial to study the compression properties of fibers, fiber assemblies, yarns and fabrics and the parameters used for representing them. In this work, an attempt has been made to design and fabricate a crushing apparatus to laterally compress the slivers before their entry into opening roller of rotor spinning frame. The modified rotor spun yarns thus produced were then studied for tensile properties, evenness, and hairiness. The results highlight the improvements in above tested parameters with increase in pre compression loads.

\section{Objectives}

$>$ To design and fabricate a pre-compression set up to compress the slivers prior to their entry into rotor spinning system.

$>$ To produce rotor spun yarns from precompressed slivers (henceforth referred to as Modified Rotor Spun Yarns).

$>$ To study the yarn properties like tenacity, elongation, hairiness, $\mathrm{U} \%$, thin, thick and neps obtained from slivers pre-compressed with four different loads. 


\section{Chapter II}

\subsection{Material and Methods}

The slivers are introduced in rotor spinning frame mounted with the pre- compression zone. Three different pre-compression loads were applied on the sliver samples before their entry into the feed roll of rotor frame. The complete processing parameters for cotton are shown in below. The yarn produced from these pre-compressed slivers were subjected to different testing methods to get the yarn quality results such as evenness\%, thin and thick faults, hairiness, single yarn tenacity and elongation. Various yarn testing instruments used are Uster tester 4, uster Tensojetansd Zweigle hairiness tester.

\begin{tabular}{|c|c|c|}
\hline \multicolumn{3}{|c|}{ Cotton Fiber } \\
\hline & Pneumafil waste & $25 \%$ \\
Mixing & Mech II Grade & $10 \%$ \\
Details & Cotton: Comber & $40 \%$ \\
& Noil & $25 \%$ \\
\hline \multicolumn{2}{|c|}{ Flat Strips } & \\
\hline \multicolumn{2}{|c|}{ Fineness } & $20 \mathrm{~mm}$ \\
\hline
\end{tabular}

Table 1: Raw Material Parameters

\subsection{Determination of Raw Material Parameters}

\subsubsection{Length}

The fiber length is measured by using the Baer sorter technique.

\subsubsection{Fineness}

Microaire values are also measured by using airflow principle. Fiber fineness influences both the strength and irregularity of yarns. The micronaire measurement employs the theory of flow of air through a porous medium. When air under constant pressure is allowed to pass through fixed mass of fiber compressed in a cylinder of fixed dimensions, the rate of flow air is found to depend on the resistances offered by fibrous plug. Cotton fibers of around $10 \mathrm{gms}$ are weighted, the fibers are inserted into the testing chamber and the cover is pressed. The micronaire value is noted manually.

\subsection{Process Flow Chart}

To study the effect of sliver pre-compression on properties of rotor spun yarn, the sliver was passed through a pre-compression unit before its entry into opening roller rotor spinning frame.

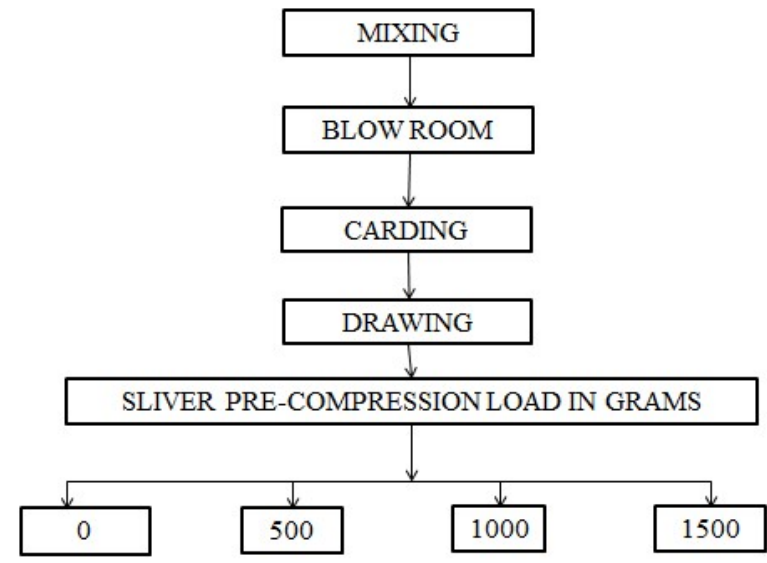

Figure 1: Process Flow chart for Modified Rotor Spun Production System

\subsection{Process Parameters}

\subsubsection{Blow Room}

Lap feed used in line: MBO, Step cleaner, PO, Condenser, Three Bladed Beater, Kirschner Beater.

$>$ Feed roller Beater setting $=8 \mathrm{~mm}$

> Grid Bar setting $=$ Minimum

Beater Speed $=750 \mathrm{rpm}$

\subsubsection{Draw Frame}

$>$ Model

$\checkmark$ Speed

$>$ Fluted Roller Setting

Total Draft

Break draft

No.of Doublings

Creel Tension Draft

Web Tension Draft

$=\mathrm{LR} \mathrm{DO} / 6$

$=240 \mathrm{rpm}$

$=38 / 38 \mathrm{~mm}$

$=6.5$

$=1.3$

$=6$

$=1.02$

$=1.02$

Delivery Hank

$=0.13$

\subsubsection{Carding}

$>$ Model

$=\mathrm{LR} \mathrm{C} 1 / 2$

Cylinder Speed

$=350 \mathrm{rpm}$

Licker in Speed

$=750 \mathrm{rpm}$

Flats Speed

Doffer Speed

$=4$ inches $/ \mathrm{min}$

$=25 \mathrm{rpm}$

$=25 \mathrm{~mm}$

$>$ Feed plate to Licker in

$=0.2 / 0.2 / 0.2$

$>$ Flats Setting

$=0.12$

\subsubsection{Rotor Frame}

$>$ Model

$>$ Opening Roller speed

$=$ ElitexBD200SNSN

$>$ Rotor Speed

$=8000 \mathrm{rpm}$

$=60000 \mathrm{rpm}$

$=4.8 / 21$

$=\mathrm{OK} 40$

$>$ Wire Type

$=20 \mathrm{~s} \mathrm{Ne}$

$>$ Count

$>$ Total Draft

$=154$

$>$ Rotor diameter

$=43 \mathrm{~mm}$ 


\subsection{Description of Sliver Compression Apparatus}

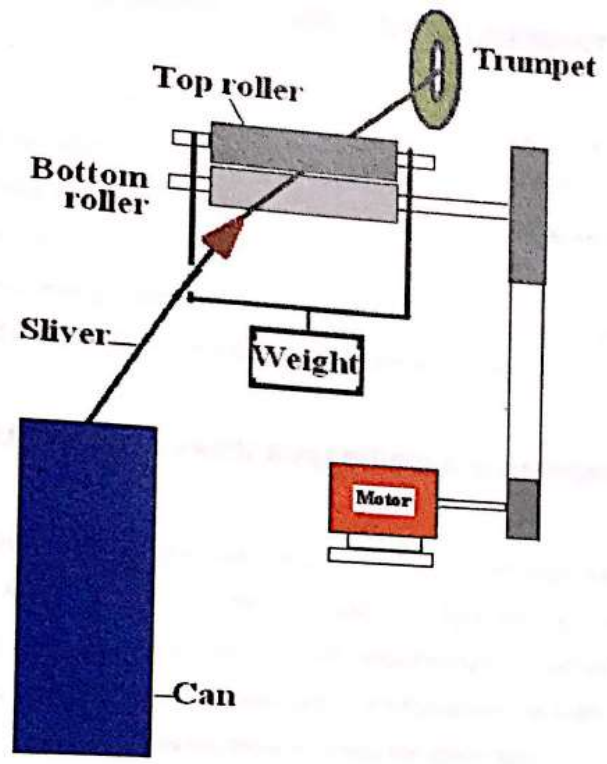

Figure 2: Schematic Diagram of Sliver Compression Apparatus

The sliver compression apparatus comprises of the following parts,

$>$ AC gear motor,25HP, $14 \mathrm{Rpm}$

$>$ Bottom roller diameter $27 \mathrm{~mm}, 3$ inches width , Axially Fluted

$>$ Synthetic covered top roller diameter $28 \mathrm{~mm}, 3$ inches width

$>$ Motor pulley diameter 2inches

$>$ Driven Pulley diameter 11.5 inches

$>$ Weigh pan carry dead weights

The bottom fluted roller is driven by the motor via the motor and driven pulleys through belt drive. Parameters like motor type, speed, driver and driven pulley diameter were carefully chosen as to keep the surface speed of bottom fluted roller at around 8inchesxper minute, which is the normal rate at which the sliver is being fed in this rotor machine.

The apparatus mounted along the path of the sliver. Attention was given so as not to stretch the sliver by any means. The sliver is loaded by applying dead weight pan which is hooked to the top roller. Loads can be changed by directly changing the weight on the weight pan. The top roller is negatively driven due to the frictional contact with the bottom roller.

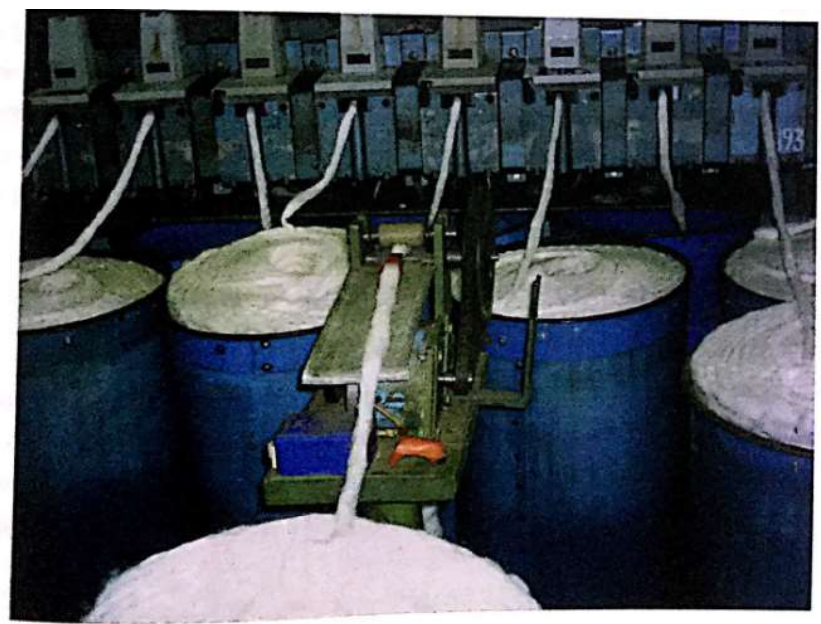

Figure 3: Sliver Compression Apparatus

\subsection{Testing Procedure for Measurement of Yarn Properties}

The yam produced from parent and pre-compressed roving's tested under standard testing atmosphere after conditioning as per ASTM standards. Uster tester 4 is used to test the unevenness and imperfections of the yarn. UsterTensojet 4 is used to test the single yarn tenacity and elongation. Zweigle hairiness tester is used to test the protruding hair count distribution of the yarn. The conditioning of samples in standard atmosphere has been maintained throughout the study.

\subsection{Determination of Yarn Evenness and Imperfections by UT4}

The yarn delivered from the rotor frame is passed through the measuring slot of evenness tester which works on the principle of capacitance. Finally the results arrived from the tester are unevenness $\%$ and imperfections. Generally thin $(-50 \%)$, thick $(+50 \%)$ and neps $(+200 \%)$ are taken into consideration for rotor spun yarn. The testing speed is for $400 \mathrm{mpm}$ and testing time is $1 \mathrm{~min}$ for each test.

\subsection{Determination of Yarn Hairiness by Zwigle Tester}

The condition yarn under standard testing atmosphere is then passed through the Zwigle hairiness tester which works on the optical principle. The image of the protruding fibers from the surface of the yarn are captured and sensed by array of detectors. Then it is accounted in a corresponding segment to get the values with the range of 1 to $12 \mathrm{~mm}$. Generally S3 value (total number of protruding hairs above $3 \mathrm{~mm}$ length) is taken into consideration for hairiness measurement. 


\subsection{Determination of Single Yarn Tenacity and Elongation}

The conditioned yarn under standard testing atmosphere is then passed through two pairs of disc rotating in counter clockwise direction against each other. Here the principle involved is constant rate of elongation. Gauge length of $500 \mathrm{~mm}$ and testing speed of $400 \mathrm{mpm}$ is maintained. Tenacity is $\mathrm{cN} / \mathrm{tex}$ and elongation in $\%$ is obtained.

\section{Results and Discussion}

The results obtained for the modified rotor yarn which has shown improvement in many aspects with respect to increase in the pre compression loads.

\subsection{Influence of Sliver Pre Compression on Evenness

\begin{tabular}{|c|c|c|c|}
\hline $\begin{array}{c}\text { Sliver } \\
\text { Hank }\end{array}$ & $\begin{array}{c}\text { Mean U\% } \\
\text { of Sliver I } \\
\text { Passage }\end{array}$ & $\begin{array}{c}\text { Mean U\% } \\
\text { of Sliver II } \\
\text { Passage }\end{array}$ & $\begin{array}{c}\text { Improvement } \\
\text { in U\% }\end{array}$ \\
\hline 0.13 & 6.6 & 6.5 & 1.5 \\
\hline
\end{tabular}

Table 1: Mass Irregularity of Cotton Sliver Measured on UT4

\subsection{Modified Rotor Yarn Evenness}

\begin{tabular}{|c|c|c|c|}
\hline $\begin{array}{c}\text { Sliver } \\
\text { hank }\end{array}$ & $\begin{array}{c}\text { Pre- Compression Load } \\
(\mathrm{g})\end{array}$ & $\begin{array}{c}\text { Yarn } \\
\mathrm{U} \%\end{array}$ & $\begin{array}{c}\mathrm{DR} \\
\mathbf{1 . 5 m}\end{array}$ \\
\hline \multirow{4}{*}{0.13} & 0 & 13.6 & 66.12 \\
\cline { 2 - 4 } & 500 & 13.01 & 54.93 \\
\cline { 2 - 4 } & 1000 & 13.15 & 56.84 \\
\cline { 2 - 4 } & 1500 & 12.57 & 55.72 \\
\hline
\end{tabular}

Table 2: Effect of Pre-Compression Load on Yarn Evenness

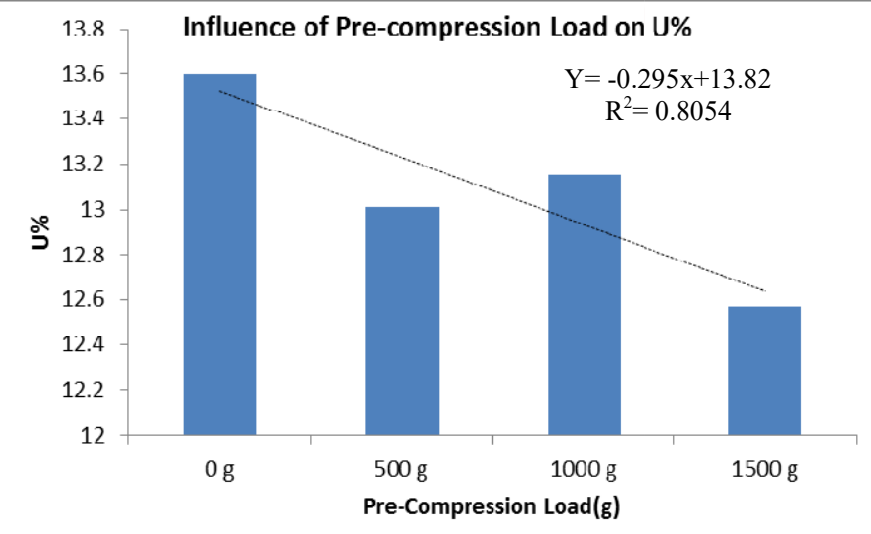

Figure 4: Effect of Pre- Compression Load on Yarn $\mathrm{U} \%$ in Cotton

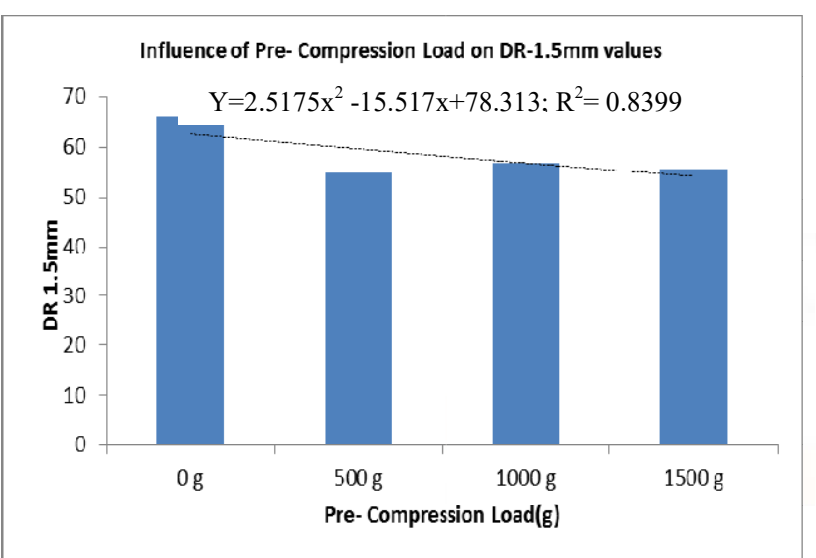

Figure 5: Effect of Pre-Compression Load on Yarn DR-1.5m in Cotton

3.3 Modified rotor Yarn Thin, Thick and Neps

\begin{tabular}{|c|c|c|c|c|}
\hline $\begin{array}{l}\text { Slive } \\
\text { r } \\
\text { Hank }\end{array}$ & $\begin{array}{l}\text { Pre- } \\
\text { Compressio } \\
\text { n Load (g) }\end{array}$ & $\begin{array}{c}\text { Thin( } \\
- \\
50 \%) \\
\text { per } \\
\text { KM }\end{array}$ & $\begin{array}{l}\text { Thick } \\
(+50 \% \\
) \text { per } \\
\text { KM }\end{array}$ & $\begin{array}{c}\text { Neps } \\
(+280 \% \\
\text { ) per } \\
\text { Km }\end{array}$ \\
\hline \multirow{4}{*}{$\begin{array}{l}0.13 \\
.10\end{array}$} & 0 & 38 & 150 & 125 \\
\hline & 500 & 25 & 173 & 105 \\
\hline & 1000 & 20 & 105 & 63 \\
\hline & $\operatorname{Mr} \cap 1500$ & 28 & 65 & 53 \\
\hline
\end{tabular}

Table 3: Effect of Pre-Compression Load on Yarn Thin Places

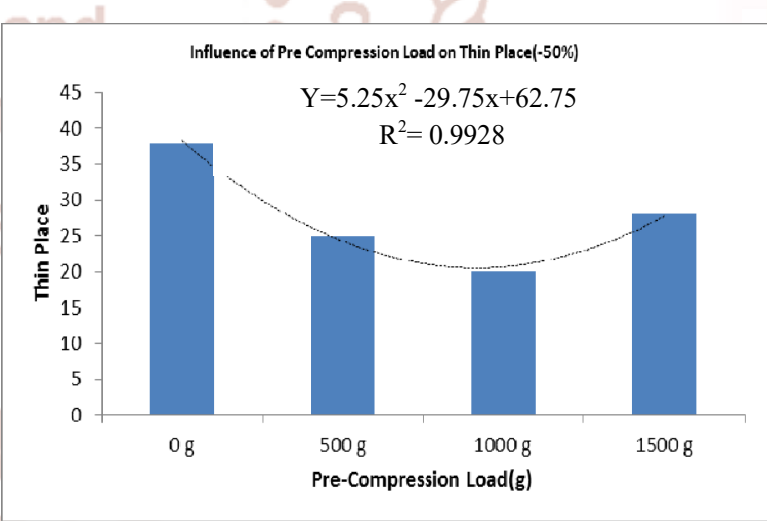

Figure 6: Effect of Pre-Compression Load on Yarn Thin Places

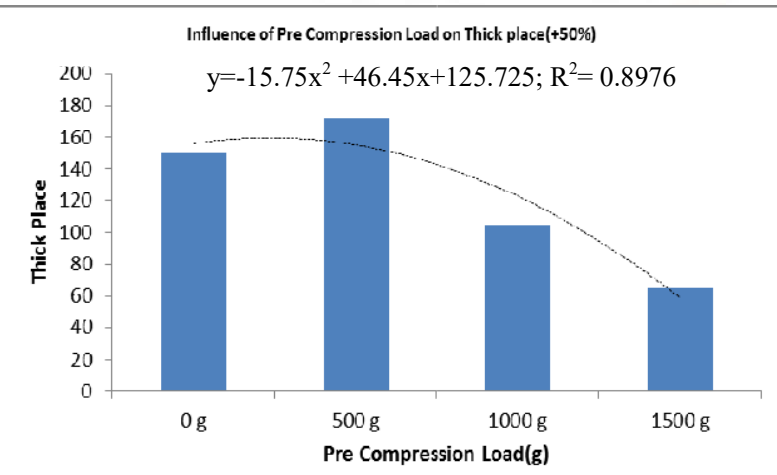

Figure 7: Effect of Pre-compression Load on Yarn Thick Places 
International Journal of Trend in Scientific Research and Development (IJTSRD) ISSN: 2456-6470

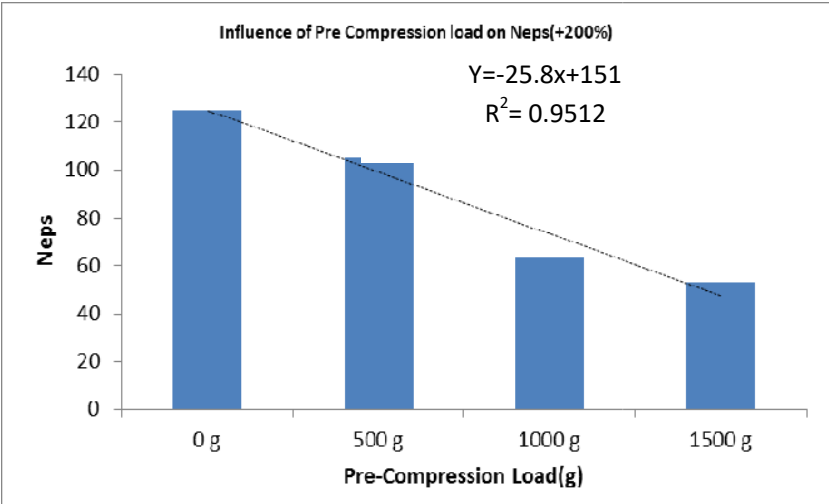

Figure 8: Effect of Pre-compression Load on Neps

3.4 Modified Rotor Yarn Tenacity, Elongation and Work of Rupture

\begin{tabular}{|c|c|c|c|c|}
\hline $\begin{array}{c}\text { Slive } \\
\mathrm{r} \\
\text { Han } \\
\mathrm{k}\end{array}$ & $\begin{array}{c}\text { Pre- } \\
\text { Compressi } \\
\text { on Load } \\
(\mathrm{g})\end{array}$ & $\begin{array}{c}\text { Single } \\
\text { yarn } \\
\text { tenaci } \\
\text { ty in } \\
\text { g/tex }\end{array}$ & $\begin{array}{c}\text { Single } \\
\text { yarn } \\
\text { elongation } \\
\%\end{array}$ & $\begin{array}{c}\text { Work } \\
\text { Ruptu } \\
\text { re gf } \\
\text { cm }\end{array}$ \\
\hline \multirow{4}{*}{0.13} & 0 & 9.51 & 5.68 & 455.3 \\
\cline { 2 - 5 } & 500 & 9.44 & 5.45 & 444.8 \\
\cline { 2 - 5 } & 1000 & 9.82 & 6.07 & 501.3 \\
\cline { 2 - 5 } & 1500 & 10.25 & 6.14 & 531.1 \\
\hline
\end{tabular}

Table 4: Effect of Pre-Compression Load on Tensile Properties

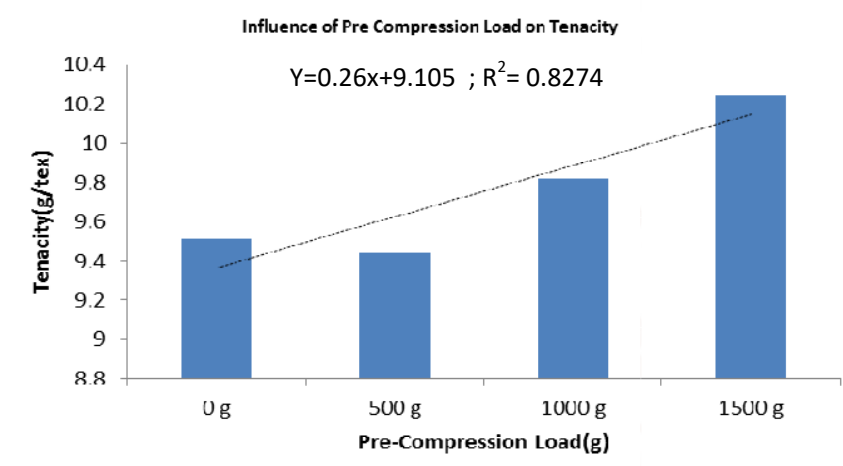

Figure 9: Effect of Pre-Compression Load on Single Yarn Tenacity

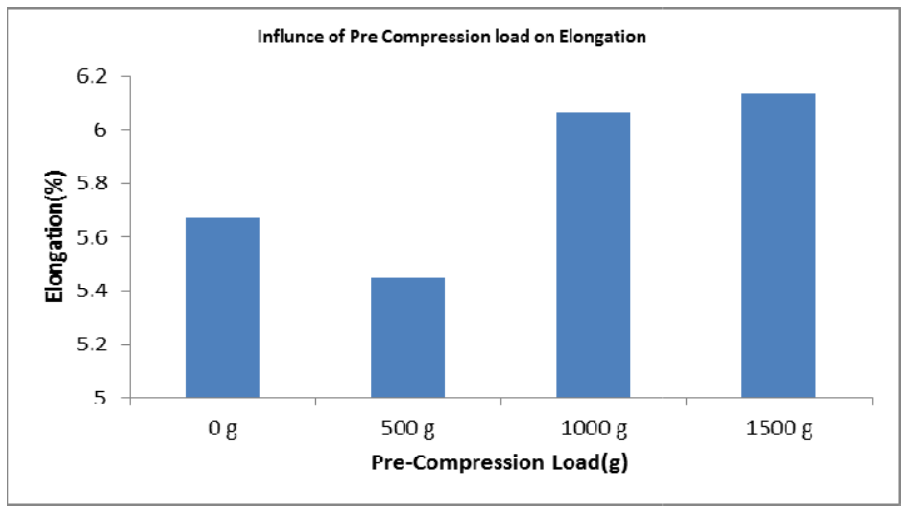

Figure 10: Effect of Pre-Compression load on single Yarn Compression
3.5 Modified Rotor Yarn Hairiness

\begin{tabular}{|c|c|c|}
\hline $\begin{array}{c}\text { Sliver } \\
\text { Hank }\end{array}$ & $\begin{array}{c}\text { Pre-Compression } \\
\text { load (g) }\end{array}$ & $\begin{array}{c}\text { Yarn Hairiness } \\
\text { S3 Value }\end{array}$ \\
\hline \multirow{4}{*}{0.13} & 0 & 72 \\
\cline { 2 - 3 } & 500 & 27 \\
\cline { 2 - 3 } & 1000 & 22 \\
\hline
\end{tabular}

Table 5: Effect of Pre-Compression Load on Yarn Hairiness

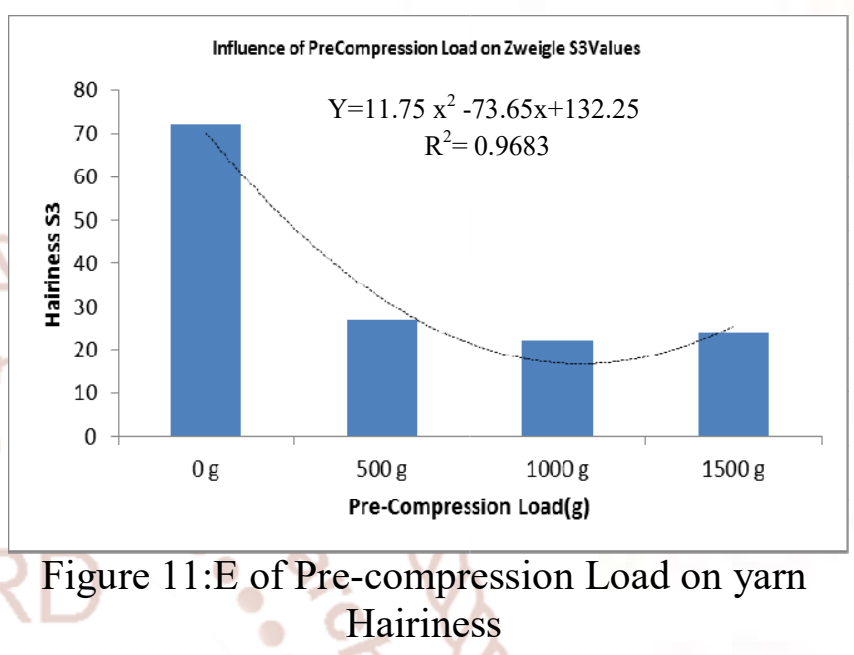

\subsection{Modified Rotor Yarn Quality Index}

The yarn quality index takes into account the key quality parameters of yarn viz., tenacity, elongation and evenness. From the above discussions, it is obvious that the yarn tenacity, elongation and evenness improve whereas hairiness and imperfections decrease with increasing precompression loads. To have a consolidated effect of all three parameters on the quality of the yarn, the yarn quality index was developed by barilla et al.

$$
(\text { YQI })=\frac{\text { Yarn Tenacity }\left(\frac{g}{t x}\right) \times \text { BreakingElongation }(\%)}{\text { Yarn Unevenness }(C V \%)}
$$

\begin{tabular}{|c|c|}
\hline Pre - Compression Load(g) & YQI \\
\hline 0 & 3.18 \\
\hline 500 & 3.16 \\
\hline 1000 & 3.63 \\
\hline 1500 & 4.01 \\
\hline
\end{tabular}

Table 6: Effect of Opening Roller Speed on YQI

\section{Conclusion}

$>$ The U\% of the modified rotor yarn reduces linearly around $8 \%$ with increase in precompression load.

Imperfections per $\mathrm{Km}$ are the least when the precompression load is 1500 grams. 
Tensile properties of modified rotor spun yarn namely tenacity, elongation and work of rupture increase by $8 \%, 7 \%$, and $18 \%$ respectively with increase in pre-compression load.

$>$ The hairiness value reduces drastically by $65 \%$ with application of pre-compression load.

$>$ The yarn quality index improves by $25 \%$ as the pre-Compression load is increased from 0 1500 grams.

\section{References}

1. A. Barella. Yam Hairiness. Text. Prog., 1983, 13, No. 1.

2. A. Barella. The Hairiness of Yarm. -Text. Prog, 1993, 24, No. 3.

3. A. Barella and A. M. Manich. Yarn Hairiness Update. Text. Prog., 1997, 26, No. 4.

4. R. Zhu and M. D. Ethridge. Predicting Hairiness for Ring and Rotor Spun Yams and Analyzing the Immrtof Fibre Properties. Text. Res. J., 1997, 67, 694-698.

5. M. Michalak and D. Kozakiewicz. Investigation of the Relationship between the Unevenness and Hairiness of Yams. In Proceedings of International Seminar on Metrology in Textile Engineering, Lodz, Poland, 1996.

6. A. V. Ukidve, V. G. Munshi, P. K. Mandhyan, and G. Viswanathan. Studies on Spectmm Density Analysison Yam Hairiness Variation. Indian J. Fibre Text. Res., 1995, 20, 92-96.

7. T. Mihajlidi, S. Milosavljsevic, K. Asanovic, L. Damnajanovic, and V. Mitrovic. An Extension of Stafftesters Application Field by Introducing Different Yam-Yam Contact Types, Faculty of Technology and Metallurgy, University of Belgrade, Belgrade, Yugoslavia, 1997.

8. G. T. Jou, G. C. East, and C A. Lawrence. A Study on Staple Filament Composite Yams Blending Irregularity. Man-made Text. India, 1995, 38, 424^30.

9. M. Cybulska. Assessment of Thread Stmcture Using Analysis Methods. In Book of Abstracts, The Fibre Society Joint International Conference, Mulhouse, France, 1997, p.347.

10. A. Barella. In Progress in Textiles, Science, and Technology, Vol. 1 \{Testing and Quality Management)(edited by V. K. Kothari), IAFL Publications, New Delhi, India, 1999, pp.232-303.
11. A. Barella. La vellosidad de los hilos. Medieion de la vellosidad (3). Rev. Indiistr. Text., 1999, No. 366, 1-81.

12. A. Barella. La vellosidad de los hilos. Medieion de la vellosidad (1), Rev. Industr. Text., 1999, No. 364, 1-77.

13. Shirley Developments Ltd. Catalogue, 1997.

14. Lawson-Hemphill Inc. Catalogue, 1997.

15. A. Barella, V. Martin, A. M. Manich, and J. P. Vigo. A New Yam-hairiness Meter. J. Text. Jnst., 1980, 71, 277-283.

16. A. Nevel and F. Arvsar. U. S. P. 6319578 (1997).

17. Lawson-Hemphill Inc. Private communication, 1998.

18. Hairiness Testing. Keisokki Report, 1998, No. 5,

19. F. Marsal. Nuevo metodoparadeterminar la vellosidad de los hilos. Rev. Industr. Text., 1998, No. 360,59-73.

20. K. Kohler. Hairiness Testing of Continuousfilament Glass Yams. /. Text. Inst., 1986, 77, 416418.

21. D. K. Wilson. Monitoring and Testing of Manufactured Fibres. Text. Prog., 1998, 28, No. 2, 20-22.

22. J. Bergmann et al. On-hne Measurement of Yam Quality.Chemiefasem/ Textilindustrie, 1998, 48, 1154-1 157.

23. Rieter AG. Broken Filament and Loop Detector. E.P. 0149764 (1989).

24. P. F. G. Industries and R. G. Grady. Broken Filament Detector. E. P. 0213587 (1985).

25. A. Nevel. Contro Uing Texturing Quality at the Tum of the Century. Int. Fiber J., 1992, 7, No. 6, $18-22$.

26. Automatic Laser Inspection of Packages. Chem. Fibres Int., 1997, 47, 304-305.

27. I. S. Tsai and W. C. Chu. A New Photoelectric Device for the Measurement of Yam Diameter and Yam Evenness. Part III: Computer-aided Online Measurement of Yam Evenness on the Ringspinning Frame. J. Text. IiLtt., 1997, 88, Part 1, $415^{\wedge} 27$.

28. A. Basu. Assessment of Yam Hairiness. In Technological Conference Research Papers of ATIRA, BTRA, NITRA, and SITRA, 1998, pp.70-76.

29. D. Kozakiewicz and M. Michalak. Comparing Hairiness Results Obtained by the Different Methods. Przeglad Wlot, 1992, 46, 2. 